\title{
Empirical Research on Assessing Index System for Integration of Information and Industrialization of Logistics Equipment Manufacturing Industry
}

\author{
Houhong Feng ${ }^{1, a}$, Ning Tao ${ }^{2, b}$, Zhangze $\mathrm{Yu}^{1, c}$ \\ ${ }^{1}$ School of Traffic \& Transportation, Dalian Institute of Science and Technology, Dalian, 116052, \\ China \\ ${ }^{2}$ Software Technology Institute of Dalian JIAOTONG University, Dalian, 116052, China \\ aemail:104654676@qq.com, bemail:daliannt@126.com, cemail:2053288767@qq.com
}

Keywords: Logistics Equipment Manufacturing Industry; Integration of Information and Industrialization; Assessing Index System

\begin{abstract}
According to GB/T23020-2013 and GB/TBBBBB - 20BB and connecting with the practical situation of the integration of information and industrialization, the article builds the assessing index system for integration of information and industrialization of logistics equipment manufacturing industry. Through empirical research, the paper evaluates the current degree of maturity of the integration by the method of analytic hierarchy process and fuzzy comprehensive method, summarizes the effect and bottleneck problems and provides the basis of how to promote the deep integration of information and industrialization in big data era.
\end{abstract}

\section{Introduction}

In recent years, the state has published some major national strategies such as the "Made in China 2025" and" Guiding opinions of the State Council on promoting "Internet+" action." It requires logistics equipment manufacturing industry to promote deep integration of information and industrialization using of large data, cloud computing, internet of things and other advanced information technology [1].

\section{Principle of Constructing the Assessing Index System}

Scientific Principles. GB / T23020-2013 is a common assessment criteria, but it can't fully satisfy the different industry's specific needs. Therefore, according to the characteristics and needs of different industries, we maintain the integrity of the evaluation framework of GB / T23020-2013, add and delete various indexes [2] .

Systematic Principle. In order to ensure the comprehensive and effective evaluation index , the construction of the index system should not only reflect the basic conditions resources and application status of integration of information and industrialization, but also take into account the competitiveness and efficiency [3].

Operability Principle. The design of the index system must have a wide range of applicability. It should be easy to construct. The evaluation data should be easy to obtain, and the data can be easily processed and analyzed by the evaluation method.

Hierarchy Principle. According to the requirements of evaluation goal, the overall objective is decomposed into interrelated multi-level evaluation index step by step from the top down. Horizontal index should be not contained and be incompatible with each other. Vertical index level should be clear.

\section{Construction of Assessing Index System for Integration of Information and Industrialization}

In this paper, the construction of assessing index system is mainly based on GB / T23020-2013 and "management system construction for integration of information and industrialization". In 
accordance with the principle of constructing the assessing index system, all levels indicators are established. The specific index system framework is shown in Figure 1.

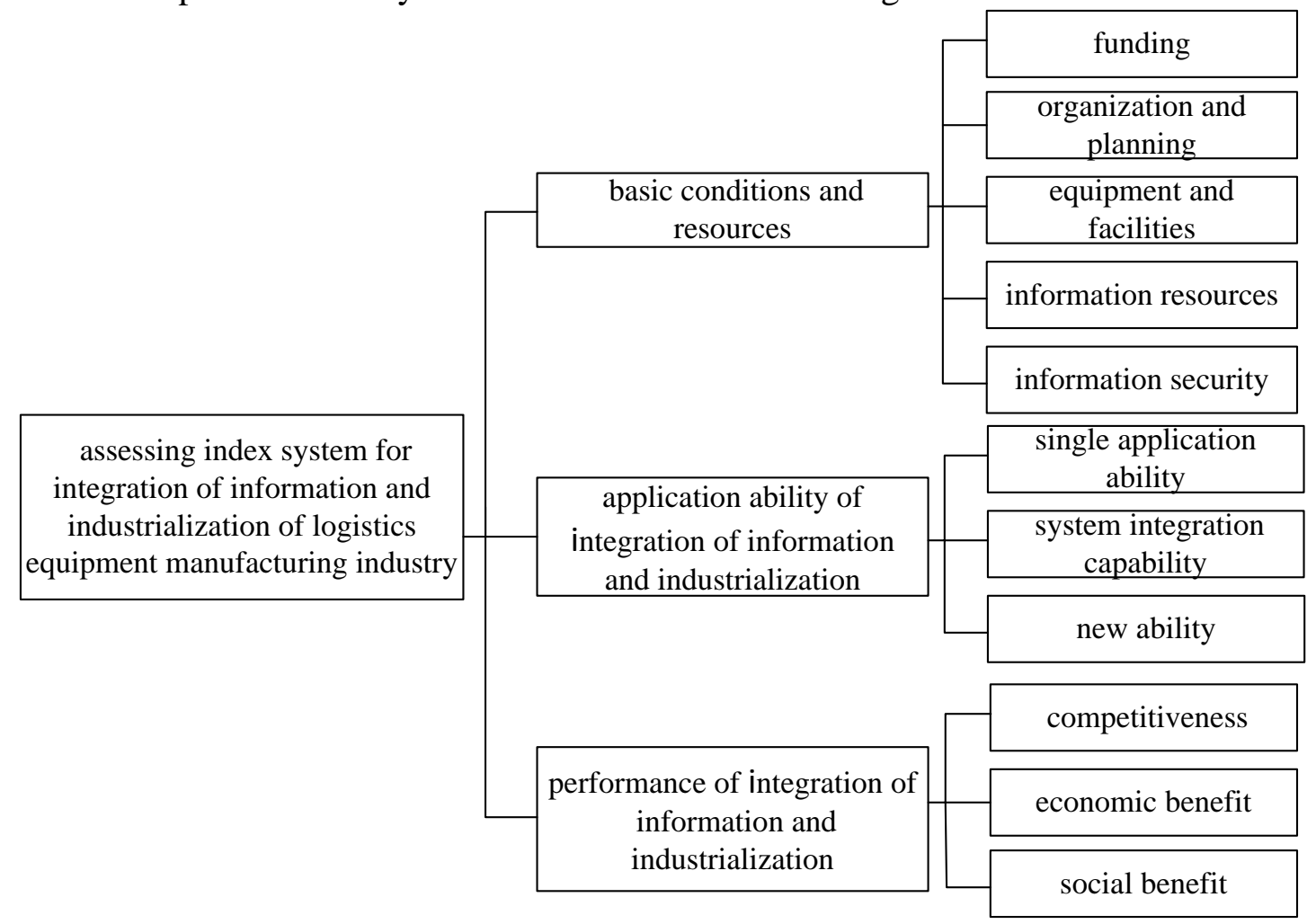

Fig.1. Assessing index system for integration of information and industrialization of logistics equipment manufacturing industry

Basic Conditions and Resources $\boldsymbol{A}_{\mathbf{1}}$. Basic conditions and resources should include financial, human, material, information and security which are the key sectors measuring basic resource guarantee level and ability .

Funding. Funding should be reasonable, moderate, stable and sustained.

Organization and Planning. Integration of information and industrialization must be a top leadership project which should set the relevant full-time information sector and there must be have the inter-disciplinary talent as a guarantee. In addition, the policy of integration of information and industrialization should be in accordance with logistics equipment manufacturing enterprise strategy .The enterprise need to draw up a document of management system construction for integration of information and industrialization.

Equipment and Facilities. The number and level of information equipment is also important. Particularly, intelligent, information and network level of logistics information collection and transmission equipment, transportation equipment and storage equipment is more critical.

Information Resources. Enterprises should realize the importance of information resources and constantly promote the standardization of information resources. Enterprises should use data mining technology to extract the enterprise information knowledge assets from the data resources.

Information Security. Enterprises personnel should have a strong sense of information security. Enterprises need provide the necessary technical conditions and facilities to ensure the safety of information security.

Application Ability of Integration of Information and Industrialization $A_{2}$. Single Application Ability. Single application ability refers to whether the information technology is integrated all links in the production chain and operating, such as product design, production, sales, procurement, inventory and other important links.

System Integration Capability. System integration capability refers to whether each individual information system can realize comprehensive and integration across departments and business, and also refers to the level of integration.

New Abilitys. The depth integration of information and industrialization can help enterprise to 
build new capacity by virtue of industrial internet technology.

Performance of Integration of Information and Industrialization $\boldsymbol{A}_{3}$. Competitiveness. By the integration of information and industrialization, enterprises may improve business efficiency, optimize the financial enhance customer satisfaction and so on.

Economic Benefit. Integration of information and industrialization can bring about sales revenue increase, lower costs, and profit growth.

Social Benefit. Integration of information and industrialization can promote the transformation of traditional manufacturing enterprises to service manufacturing enterprises. In addition, it plays an important role in saving the energy resources and preserving the ecological environment.

\section{Evaluation Method of Integration of Information and Industrialization}

The evaluation index system constructed in the previous article is a multi-objective, multi-level and multi-factor complex system. Some index can be accurately described with specific numerical values, and some index which have strong ambiguity can't be expressed with exact values, Therefore, this paper uses AHP and FCE to evaluate the integration of information and industrialization.

Determine Indexes Weight. In this paper, AHP is adopted to determine indexes weight. First, we use the importance scale to compare the indexes in pairs, and construct the judgment matrix $A=\left(a_{i j}\right)$. Second, carry out normalization processing for each row to get $B=\left(b_{\mathrm{ij}}\right), b_{i j}=a_{i j} / \sum_{i=1}^{n} a_{i j}, i, j=1,2, \ldots, n$, sum according to the line to obtain $C=\left(C_{1}, C_{2} \ldots, C_{\mathrm{n}}\right)^{T}, C_{i}=\sum_{j=1}^{n} b_{i j}, i=1,2, \ldots, n$, and carry out normalization processing for $C$ to get approximate characteristic vector $W=\left(W_{1}, W_{2} \ldots, W_{n}\right)^{T}$, $W_{i}=C_{i} / \sum_{i=1}^{n} c_{i}, i=1,2, \ldots, n$. Third, Calculate $\lambda_{\max }=\frac{2}{n} \sum_{i=2}^{n} \frac{A W}{W_{i}}$ as the approximate value of the Max-Eigen. Fourth, use $C R=C I / R I$ for consistency check, $C I=\left(\lambda_{\max }-n\right) / n-1, R I$ is average random consistency scale.

Set up an Evaluation Level Set. Set the evaluation level set $V=$ \{primary level, intermediate level, higher level, advanced level $\}$, according to 10 points scoring, then the evaluation level set $V=(3,5,7$, 9).

Construct Fuzzy Evaluation Sample Matrix. We can organize some relevant personnel to evaluate the indicators. For the indicators which can be quantitatively calculated, we can decide which grade it belongs to according to the calculated value. For the strong fuzzy qualitative indicators, we can directly determine which grade it belongs to.

Fuzzy Comprehensive Evaluation. According to the above weight and evaluation matrix, the fuzzy comprehensive evaluation vector can be calculated. Based on the evaluation level, the number of components is converted and we can draw a conclusion.

\section{Empirical Research}

Determine Indexes Weight for Integration of Information and Industrialization. The weight of the index is determined by consulting the experts in the relevant field, as well as the reference weights of Chen Jie, Zhou Jian [2016] [4] and Zhang Yuke [2013] [5]. According to the 1-9 importance scale method, the relevant judgment matrix is constructed and the consistency check is carried out. The results are shown in Table 1.

Construct Fuzzy Evaluation Matrix. This evaluation collected 100 samples of logistics equipment manufacturing enterprises through questionnaire, telephone survey and online research, which is shown as Table 2. The samples covered the pilot enterprises which implement management system construction for integration of information and industrialization, small and medium-sized enterprises and micro-enterprises. 
Table 1 Index weight list

\begin{tabular}{c|c|c}
\hline Index weight & Max-Eigen & consistency check \\
\hline$A_{1}(0.345,0.159,0.273,0.120,0.102)$ & $\lambda_{\max }=5.033$ & $C R=0.007<0.1$ \\
\hline$A_{2}(0.613,0.269,0.118)$ & $\lambda_{\max }=3.018$ & $C R=0.018<0.1$ \\
\hline$A_{3}(0.263,0.573,0.191)$ & $\lambda_{\max }=3.309$ & $C R=0.037<0.1$ \\
\hline$A(0.313,0.486,0.201)$ & $\lambda_{\max }=3.001$ & $C R=0.001<0.1$ \\
\hline
\end{tabular}

Table 2 Fuzzy evaluation matrix $R$

\begin{tabular}{|c|c|c|c|c|c|}
\hline first class indicator & second class indicator & $\begin{array}{l}\text { primary } \\
\text { level }\end{array}$ & $\begin{array}{l}\text { intermedi } \\
\text { ate level }\end{array}$ & $\begin{array}{l}\text { higher } \\
\text { level }\end{array}$ & $\begin{array}{l}\text { advanced } \\
\text { level }\end{array}$ \\
\hline \multirow{5}{*}{$\begin{array}{l}\text { basic conditions and } \\
\text { resources }\end{array}$} & funding & 11 & 25 & 46 & 18 \\
\hline & organization and planning & 18 & 32 & 45 & 15 \\
\hline & equipment and facilities & 12 & 30 & 35 & 30 \\
\hline & information resources & 15 & 25 & 41 & 19 \\
\hline & information security & 20 & 25 & 38 & 17 \\
\hline \multirow{3}{*}{$\begin{array}{l}\text { application ability of } \\
\text { integration of } \\
\text { information and } \\
\text { industrialization }\end{array}$} & single application ability & 10 & 45 & 20 & 25 \\
\hline & system integration capability & 39 & 16 & 35 & 10 \\
\hline & new ability & 70 & 17 & 8 & 5 \\
\hline \multirow{3}{*}{$\begin{array}{l}\text { performance of } \\
\text { integration of } \\
\text { information and } \\
\text { industrialization }\end{array}$} & competitiveness & 35 & 35 & 24 & 6 \\
\hline & economic benefit & 24 & 36 & 28 & 12 \\
\hline & social benefit & 40 & 35 & 17 & 8 \\
\hline
\end{tabular}

Evaluate indexes at all levels:

$\begin{array}{ll}B_{1}=A_{1} * R_{1}=(0.10,0.24,0.42,0.24) & F_{1}=B_{1} * V^{\mathrm{T}}=6.6 \\ B_{2}=A_{2} * R_{2}=(0.25,0.34,0.22,0.19) & F_{2}=B_{2} * V^{\mathrm{T}}=5.7 \\ B_{3}=A_{3} * R_{3}=(0.50,0.34,0.09,0.07) & F_{3}=B_{3} * V^{\mathrm{T}}=4.5 \\ B=A^{*} R=(0.25,0.31,0.26,0.18) & F=B^{*} V^{\mathrm{T}}=5.7\end{array}$

Empirical Analysis. We can conclude from the above evaluation data. The Score in the Basic Conditions and Resources is Highest. Above $66 \%$ of enterprises is in a more senior level. The results show that the basic conditions and resources which are needed for the integration of information and industrialization have been basically ready. The enterprises pay for attention to the integration of information and industrialization, capital investment is basically stable, hardware and software resources are more fully prepared.

Application Ability of Integration of Information and Industrialization is in the Intermediate Level as a Whole. Production, inventory, procurement and other important business aspects have realized informatization, but IT level in energy environmental protection and security management is not high. A few key enterprises have a high level of integration which have step into the integrated promotion and innovation stage and have created a new ability under the environment of informatization.

The Score in the Performance of Integration of Information and Industrialization is Lower. The conclusion indicates that only $16 \%$ of the mature enterprises have good competitiveness and social and economic benefits in the process of integration.

The Integration of Information and Industrialization Maturity Score is 5.7, which Indicates that the Integration Levels of Logistics Equipment Manufacturing Industry is in the Process from Intermediate Stage to the Higher Level. The integration process is facing "integrated" and the plight 
of how to innovate in the Internet+ environment. If they overcome these bottlenecks, the performance will achieve leapfrog growth and the dividend will be completely released about integration of information and industrialization.

\section{Conclusion}

The article builds the assessing index system for integration of information and industrialization of logistics equipment manufacturing industry. Through empirical research, the AHP and FCE are used to evaluate the maturity of the integration of information and industrialization. The paper summarizes the effectiveness of integration of the logistics equipment manufacturing industry, finds out the bottleneck problem of the integration of the equipment manufacturing industry and put forward the concrete strategy of deepening the integration of informatization and Chinese manufacturing industry in the era of large data.

\section{Acknowledgement}

This work is supported by the General Project of Liao Ning Province Science and Research (W2015076),Liaoning Province Training Programs for Innovation and Entrepreneurship National Training Programs of Innovation and Entrepreneurship for Undergraduate(201613207000035)and Liaoning province education science "The thirteen Five-Year Guideline" (JG16DB061).

\section{References}

[1] Libao Yu and so on, The empirical research of manufacturing enterprise informatization and industrialization integration index system-In the case of Fujian province, Machine Design and Manufacturing Engineering,2015

[2] Zhou Jian and so on, Index system construction for assessing integration of information and industrialization in manufacturing enterprises, Computer Integrated Manufacturing Systems, 2013

[3]Yan Feng and so on, Research on Integration of Informationization and Industrialization Development Measure of Coal Industry from the Perspective of System Theory, Science and Technology Management Research, 2016

[4]Chen Jie, Empirical research on assessing system for integration of information and industrialization of industrial enterprises, Manufacturing Automation, 2016

[5]Zhangyu Ke and so on, Research on the Comprehensive Evaluation of the Intergration between Informationization and Industrialization, Journal of Hebei University (Philosophy and Social Science), 2013 